Research Paper

\title{
Targeting ALDH1A1 by disulfiram/copper complex inhibits non-small cell lung cancer recurrence driven by ALDH-positive cancer stem cells
}

\author{
Xinwei Liu ${ }^{1,2}$, Lihui Wang ${ }^{1,2}$, Wei Cui ${ }^{1}$, Xiangzhong Yuan ${ }^{1}$, Lulu Lin ${ }^{1}$, Qi Cao ${ }^{1}$, Nannan \\ Wang $^{1,2}$, Yi Li ${ }^{1,2}$, Wei Guo ${ }^{1}$, Xun Zhang ${ }^{1}$, Chunfu Wu ${ }^{1,2}$, Jingyu Yang ${ }^{1,2}$ \\ ${ }^{1}$ Department of Pharmacology, Shenyang Pharmaceutical University, Shenyang, P.R. China \\ ${ }^{2}$ Benxi Institute of Pharmaceutical Research, Shenyang Pharmaceutical University, Benxi, P.R. China \\ Correspondence to: Chunfu Wu, email: wucf@syphu.edu.cn \\ Jingyu Yang, email: yangjingyu2006@gmail.com \\ Keywords: disulfiram/copper, ALDHIA 1, cancer stem cell, NSCLC, recurrence \\ Received: February 03, $2016 \quad$ Accepted: July 26, $2016 \quad$ Published: August 16, 2016
}

\section{ABSTRACT}

The existence of cancer stem cells (CSCs) in non-small cell lung cancer (NSCLC) has profound implications for cancer therapy. In this study, a disulfiram/copper (DSF/ $\mathrm{Cu}$ ) complex was evaluated in vitro and in vivo for its efficacy to inhibit CSCs, which drive recurrence of NSCLC. First, we investigated whether DSF/Cu could inhibit ALDHpositive NSCLC stem cells in vitro and tumors derived from sorted ALDH-positive CSCs in vivo. DSF/Cu $(0.5 / 1 \mu \mathrm{mol} / \mathrm{I})$ significantly inhibited the expression of stem cell transcription factors (Sox2, Oct-4 and Nanog) and reduced the capacities of NSCLC stem cells for self-renewal, proliferation and invasion in vitro. Regular injections with DSF/Cu $(60 / 2.4 \mathrm{mg} / \mathrm{kg})$ reduced the size of tumors derived from sorted ALDHpositive stem cells. Two other NOD/SCID xenograft models were used to determine whether DSF/Cu could target NSCLC stem cells and inhibit tumor recurrence in vivo. DSF/Cu treatment eliminated ALDH-positive cells and inhibited tumor recurrence, which was reflected by reduced tumor growth in recipient mice that were inoculated with tumor cells derived from DSF/Cu-treated cells or primary xenografts. RNA interference and overexpression of ALDH isozymes suggested that ALDH1A1, which plays a key role in ALDH-positive NSCLC stem cells, might be the target of the DSF/ Cu complex. Collectively, our data demonstrate that DSF/Cu targets ALDH1A1 to inhibit NSCLC recurrence driven by ALDH-positive CSCs. Thus, the DSF/Cu complex may represent a potential therapeutic strategy for NSCLC patients.

\section{INTRODUCTION}

The cancer stem cell model proposes that tumor progression, drug resistance, metastasis, and relapse after therapy may be driven by a subset of cells within a tumor. This phenomenon is a functionally important example of intra-tumor heterogeneity [1, 2]. During the past few years, cancer stem cells (CSCs) have been identified in, and isolated from, solid tumors such as breast, brain, colon, pancreatic, and prostate tumors [3-7]. The identification of CSCs has important implications for future therapeutic approaches. Recent evidence suggests that like other tumors, human lung cancers may also harbor CSC populations [8, 9]. However, identification and targeting of human lung CSCs has been hampered by the lack of reliable lung cancer stem cell markers [10].

The aldehyde dehydrogenase (ALDH) family comprises cytosolic isoenzymes responsible for oxidizing intracellular aldehydes, including the oxidation of retinol to retinoic acid in early stem cell differentiation [11]. Recent evidence suggests that ALDH activity has also identified CSCs in a variety of tumor types [12-22]. Disulfiram (DSF) is an aldehyde dehydrogenase inhibitor that was used as a vermicide in the 1930s and for alcohol aversion therapy since the 1940s [11]. Accumulating evidence demonstrates that DSF has strong anticancer activity against certain types of cancer both in vitro and in mouse models [23-26]. Inhibition of ALDH activity 
has been investigated as a potential strategy to eliminate cancer stem cells [27], and the results suggest that DSF may specifically target cancer stem cell subpopulations. Also, previous studies indicated that the cytotoxicity of DSF is copper $(\mathrm{Cu})$-dependent [26, 28-30]. In breast cancer, DSF and copper treatment inhibits NF- $\kappa \mathrm{B}$ activity, elevates ROS levels and decreases the number of breast cancer stem cells in vitro [31]. DSF, either alone or in combination with copper, inhibits the growth of lung cancer cells in vitro [32]. These findings led us to investigate the effect of DSF/copper complex treatment on ALDH-positive NSCLC stem cells in vitro and in vivo.

In this study, we examined the efficacy of the DSF/ $\mathrm{Cu}$ complex against ALDH-positive NSCLC stem cells in cell lines and lung cancer xenografts. Our in vivo data showed that the DSF/Cu complex was more effective than DSF alone at eliminating ALDH-positive cells and inhibiting tumor recurrence, as reflected by the inhibition of tumor growth in recipient mice that were inoculated with tumor cells derived from DSF/Cu-treated cell lines or primary xenografts. Furthermore, we investigated the stem cell-related function and significance of ALDH isozymes in NSCLC cell lines. Our data showed that ALDH1A1, which plays a key role in ALDH-positive NSCLC stem cells, is the target of the DSF/Cu complex.

\section{RESULTS}

\section{ALDH-positive cells represent cancer stem cells in NSCLC cell lines}

ALDH activity can be determined by the Aldefluor assay, which has been used to identify CSCs in a variety of tumor types [12-22]. Although previous reports have characterized the ALDH-positive CSC population in some NSCLC cell lines [21, 22], it is necessary to confirm the identity of CSCs in specific experimental environments. Therefore, Aldefluor assays followed by FACS analysis were used to assess the presence of a cell population with ALDH activity, and then colony forming assays were used to compare the colony forming capacity of ALDH-positive and ALDH-negative cells in four NSCLC cell lines (NCI-H1299, NCI-H460, NCI-H522 and A549). We found that all cell lines had a small ALDH-positive population, with $2.0 \%(2.00 \pm 0.03)$ in NCI-H1299, $1.6 \%(1.60 \pm$ $0.67)$ in NCI-H460, $1.9 \%(1.87 \pm 0.04)$ in NCI-H522 and $0.2 \%(0.23 \pm 0.04)$ in A549 (Figure 1A and Supplemental Figure S1). However, only in the NCI-H1299 and NCI-H460 cell lines did the ALDH-positive cells show a significantly higher colony-forming efficiency than the ALDH-negative cells, as judged by clonal assays (Figure $1 \mathrm{~B}$ and Supplemental Figure S1). These data indicated that the ALDH-positive subpopulation of the NCI-H1299 and NCI-H460 cell lines possessed a high self-renewal capacity. We also found that some other NSCLC cell lines, such as A549, contain cells with high colony forming efficiency that are positive for other putative CSC markers, such as CD133 (Supplemental Figure S2). Therefore, the NCI-H1299 and NCI-H460 cell lines were chosen as models for further research into the role of ALDH in CSCs.

Oct4, Sox2 and Nanog are consistently detected in human CSCs [33], so we compared their expression in ALDH-positive and ALDH-negative cells. Our data showed that Nanog, Oct-4 and Sox 2 were expressed at higher levels in ALDH-positive NCI-H1299 cells than in ALDH-negative NCI-H1299 cells, suggesting that in the NCI-H1299 cell line, ALDH expression may be essential for maintaining self-renewal and tumorigenesis (Figure 1C). To further explore whether ALDH is a single CSC marker in NSCLCs, H1299 cells were double-stained with Aldefluor and another putative NSCLC stem cell marker, CD133 (PE). As shown in Figure 1D, the whole ALDHpositive population (1.4\%) also showed a high level of CD133 expression. The proportion of ALDH+/CD133cells was $0.0 \%$. There was a high degree of overlap between CD133 and ALDH expression.

The gold standard for identification of CSCs is whether the cells can preferentially initiate tumor development in animal models [2]. To investigate possible differences in tumor-forming potential between the ALDH-positive and ALDH-negative sorted cells, $5 \times 10^{3}$ ALDH-positive and $5 \times 10^{3}$ ALDH-negative NCI-H1299 cells were injected under the skin in opposite sides of NOD/SCID mice (4 mice in each group). After 7 weeks, the ALDH-positive NCI-H1299 cells generated much larger tumors than the ALDH-negative cells in all the mice (Figure 1E). To elucidate whether ALDHpositive H1299 cells could create larger tumors with heterogeneity in vivo, Aldefluor analysis was carried out on disassociated cells from the first generation tumor engrafts. The engrafted tumors derived from ALDHpositive cells gave rise to $4.7 \%$ ALDH-positive cells and the tumors derived from ALDH-negative cells gave rise to $1.4 \%$ ALDH-positive cells (Figure 1F). Living cells from the dissociated tumor engrafts were sorted for secondary xenografts. ALDH-positive and ALDHnegative cells were inoculated in opposite sides of NOD/SCID mice at a dose of 5,000 or 500 cells. The results showed that the secondary xenograft tumors that developed from the ALDH-positive cells were larger than the tumors from ALDH-negative cells, especially in the 500 cells group (Figure 1G). Our in vivo data suggested that ALDH-positive NCI-H1299 cells possess the unique features of cancer stem-like cells, including initiation of tumorigenesis, self-renewal, and the reinitiation of serially transplantable tumors.

Taken together, the results of the in vivo and in vitro assays indicated that within some NSCLC cell lines, the ALDH-positive cells have the broadest self-renewal and differentiation potential in vitro and the highest growth potential in vivo. 
A
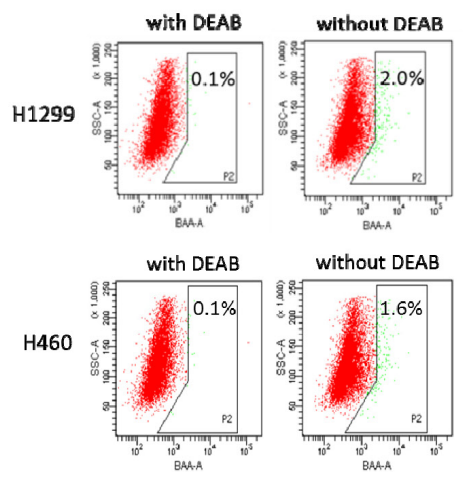

C

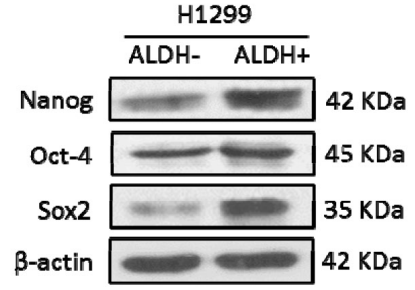

B
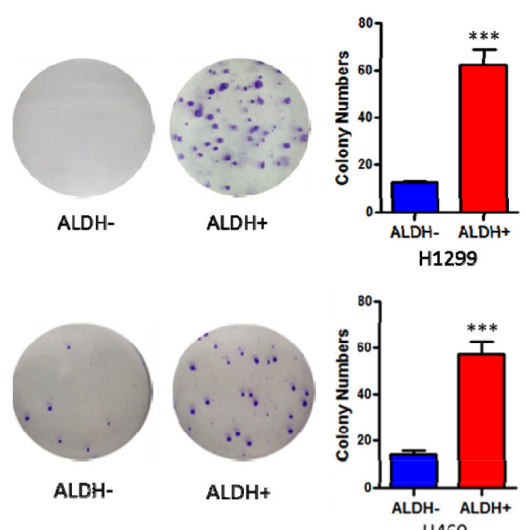

D

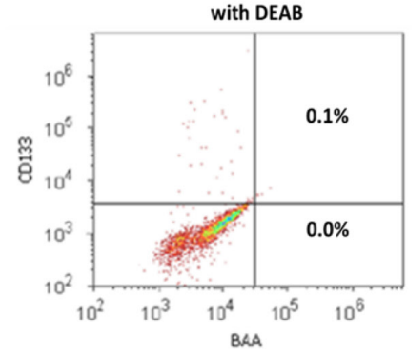

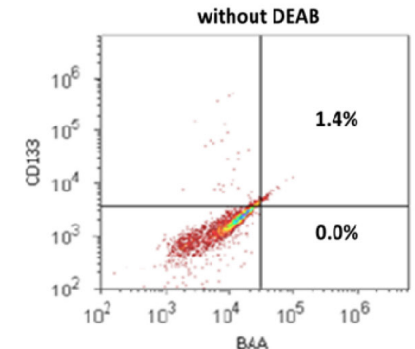

$\mathbf{E}$

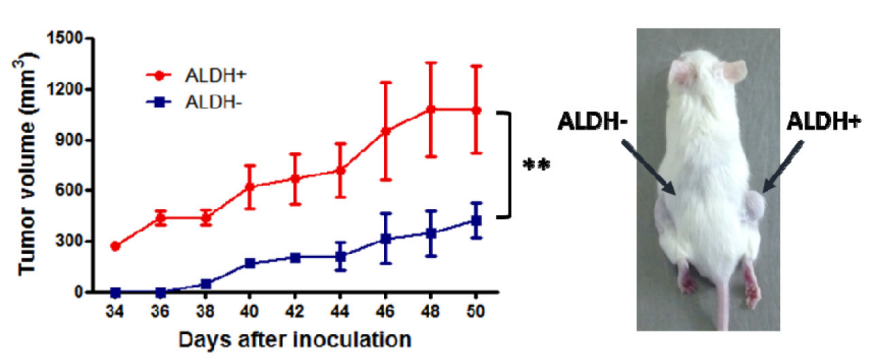

$\mathbf{F}$

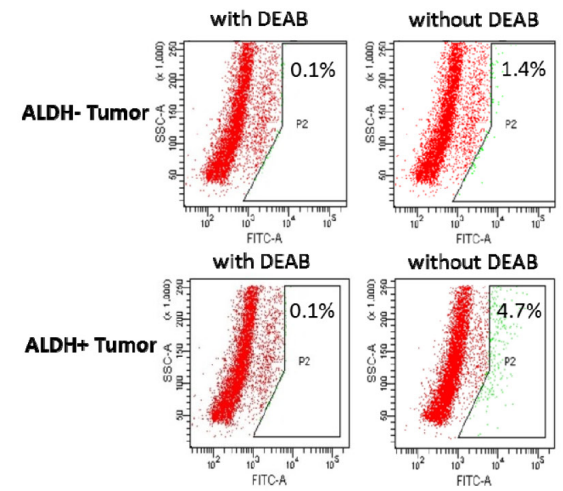

G

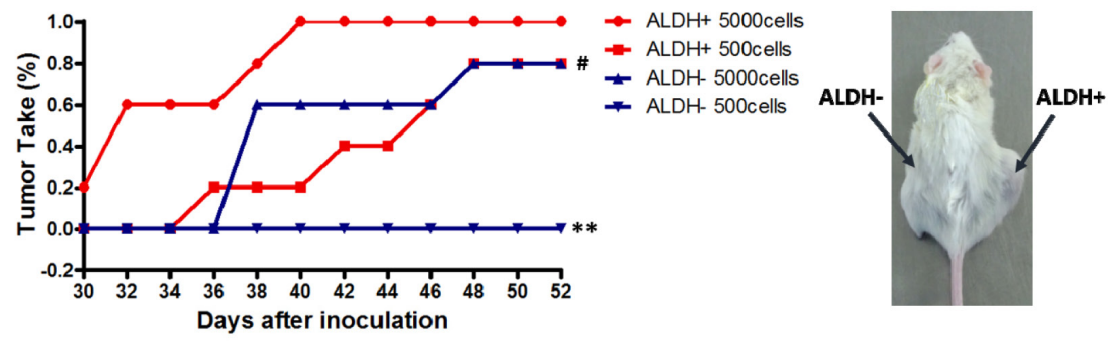

Figure 1: ALDH-positive cells represent cancer stem cells in some NSCLC cell lines. A. ALDH-positive and ALDH-negative cells were isolated from the indicated NSCLC cell lines by FACS. Brightly fluorescent ALDH-expressing cells (ALDH-positive cells) were detected in the green fluorescence channel (BAA) using flow cytometry. DEAB, a specific inhibitor of ALDH, was used to establish the baseline fluorescence of these cells and to define the ALDH-positive region. B. Analysis of cell colony numbers in colony forming assays of ALDH-positive and ALDH-negative cells $\left(* * * P<0.001, \chi^{2}\right.$ test). C. Analysis of stem cell transcription factors by western blotting. D. Double staining of Aldefluor and CD133 (PE) in NCI-H1299 cells. E. Comparison of primary xenograft formation by sorted ALDHpositive and ALDH-negative NCI-H1299 cells in NOD/SCID mice ( ${ }^{*} P<0.01,2$-tailed $t$ test). F. The percentage of ALDH-positive cells in xenograft tumors derived from ALDH-positive and ALDH-negative cells. G. Comparison of tumor take (\%) in NOD/SCID mice with secondary xenografts of ALDH-positive and ALDH-negative cells taken from primary xenograft tumors $\left(* * P<0.01, \chi^{2}\right.$ test, compared with the ALDH+ 500 cells group; $\# P<0.05, \chi^{2}$ test, compared with the ALDH+ 5000 cells group). 


\section{$\mathrm{DSF} / \mathrm{Cu}$ inhibits the stemness of NSCLCs in vitro}

As shown above, ALDH-positive cells represent the stem cell population in some NSCLC cell lines. Therefore, DSF, which has been proved to be an irreversible inhibitor of ALDHs, may also inhibit NSCLC stem cells. Firstly, we examined the effects of DSF and DSF/Cu on the ALDHpositive populations in NCI-H1299 and NCI-H460 cells. As shown in Figure 2A and Supplemental Figure S3, both DSF $(0.02 \mu \mathrm{M}, 0.1 \mu \mathrm{M}$ and $0.5 \mu \mathrm{M})$ alone and the DSF/Cu complex $(0.02 / 1 \mu \mathrm{M}, 0.1 / 1 \mu \mathrm{M}$ and $0.5 / 1 \mu \mathrm{M})$ significantly reduced the proportion of ALDH-positive cells (control: $2.03 \% \pm 0.38 \%$; DSF, $0.5 \mu \mathrm{M}$ : $0.33 \% \pm 0.04 \%$; DSF $/ \mathrm{Cu}$, $0.5 / 1 \mu \mathrm{M}: 0.07 \% \pm 0.04 \%$ ).

Next, we examined the inhibitory effects of DSF, $\mathrm{Cu}$ and $\mathrm{DSF} / \mathrm{Cu}$ treatment on the expression of the stem cell transcription factors Nanog, Sox 2 and Oct-4. As shown in Figure $2 \mathrm{~B}, \mathrm{DSF} / \mathrm{Cu}$ dramatically reduced the expression of all three stem cell transcription factors in a concentrationdependent manner, and the inhibitory activity of DSF/Cu was far more potent than DSF alone.

We further tested the ability of DSF and DSF/ $\mathrm{Cu}$ to inhibit the colony-forming efficiency of ALDHpositive cells derived from NCI-H1299 cells. As shown in Figure $2 \mathrm{C}, \mathrm{DSF} / \mathrm{Cu}(0.5 / 1 \mu \mathrm{M})$ had a significantly stronger inhibitory effect on colony formation than DSF alone $(0.5 \mu \mathrm{M})$. We also compared the ability of DSF/ $\mathrm{Cu}$ to inhibit the colony-forming ability of cell lines which harbor ALDH-positive CSCs and those which do not harbor ALDH-positive CSCs. We examined the efficacy of DSF/Cu on the ALDH-positive subsets in the NCI-H1299, NCI-H460 and A549 cell lines. As shown in Supplemental Figure S5, DSF/Cu $(0.5 / 1 \mu \mathrm{M})$ inhibited the colony-forming ability of ALDH-positive cells in all these lung cancer cell lines. However, the inhibitory efficacy in A549 cells $(79.5 \%)$ was lower than in NCI-H1299 and NCI-H460 cells $(100 \%)$. Thus, these results demonstrate that $\mathrm{DSF} / \mathrm{Cu}$ may be useful in the treatment of lung tumors that harbor a subpopulation of ALDH-positive CSCs.

Similar results were also observed in tumorsphere forming assays. It has been shown that cancer stem/ progenitor cells are enriched in non-adherent spherical clusters of cells [2]. To evaluate whether DSF and DSF/ $\mathrm{Cu}$ can inhibit the formation of tumorspheres in vitro, we exposed tumorspheres to DSF $(0.5 \mu \mathrm{M}), \mathrm{Cu}(1 \mu \mathrm{M})$ and $\mathrm{DSF} / \mathrm{Cu}(0.5 / 1 \mu \mathrm{M})$ for $24 \mathrm{~h}$. As shown in Figure 2D and Supplemental Figure S6, DSF and DSF/Cu inhibited the formation of tumorspheres. The inhibitory efficacy of copper may be due to ROS formation, which is promoted by copper ions. We also evaluated the anti-proliferative effects of DSF in NCI-H1299 and NCI-H460 cells by MTT assay (Supplemental Figure S4). The data showed that $\mathrm{DSF} / \mathrm{Cu}$ significantly inhibited the proliferation of ALDH-positive NSCLC stem cells.

The capacity for invasion and metastasis may also be an important property of CSCs [2]. Therefore, the invasion of NCI-H1299 and NCI-H460 cells was measured by transwell assays after treatment with DSF $(0.5 \mu \mathrm{M}), \mathrm{Cu}(0.5 \mu \mathrm{M})$ and DSF/Cu $(0.1 / 0.5 \mu \mathrm{M}, 0.25 / 0.5$ $\mu \mathrm{M}$ and $0.5 / 0.5 \mu \mathrm{M})$ for $24 \mathrm{~h}$. The results showed that $\mathrm{DSF} / \mathrm{Cu}$ dramatically reduced the fetal bovine serum (FBS)-induced invasion of NSCLCs in a concentrationdependent manner (Figure 2E and Supplemental Figure S7).

Taken together, these results demonstrated that treatment with $\mathrm{DSF} / \mathrm{Cu}$, but not DSF alone, significantly inhibited the stemness of ALDH-positive cells in vitro.

\section{DSF/Cu inhibits ALDH-positive NSCLC stem cells in vivo}

To determine whether DSF/Cu can inhibit ALDHpositive NSCLS stem cells in vivo, we used a xenograft model of ALDH-positive NCI-H1299 cells in NOD/SCID mice. ALDH-positive cell populations were analyzed using the Aldefluor assay and sorted by FACS. Tumor cells were implanted into three groups of mice (five mice in each group).

Two weeks after cell inoculation, animals were intravenously injected with $0.9 \% \mathrm{NaCl}$ solution (control) or DSF (DSF-loaded lipid emulsion, $30 \mathrm{mg} / \mathrm{kg}$ and $60 \mathrm{mg} /$ $\mathrm{kg}$ ) with $\mathrm{Cu}$ (intragastric administration, $2.4 \mathrm{mg} / \mathrm{kg}$ ) every two days. After 2 weeks of treatment, tumors in the DSF/ $\mathrm{Cu}(30 / 2.4 \mathrm{mg} / \mathrm{kg})$ mice were $62.4 \%$ of the size of those in the control animals, and tumors in the $\mathrm{DSF} / \mathrm{Cu}(60 / 2.4$ $\mathrm{mg} / \mathrm{kg}$ ) mice were $46.6 \%$ of the size of those in the control animals (Figure 3A). DSF/Cu had no apparent toxicity as determined by body weight measurement (Figure 3B). The inhibitory efficacy of DSF/Cu treatment on the expression of the stem cell transcription factors Nanog and Oct-4 in tumor tissues was also examined. As shown in Figure 3C, $\mathrm{DSF} / \mathrm{Cu}$ treatment inhibited the expression of Nanog and Oct-4 in a dose-dependent manner. These results suggested that $\mathrm{DSF} / \mathrm{Cu}$ was able to eliminate NSCLC stem cells in xenografted ALDH-positive cells.

\section{Effects of DSF/Cu treatment on NSCLC stem cell numbers in vitro and tumor recurrence in vivo}

To determine whether DSF/Cu can inhibit tumor regrowth in vivo, we assessed the functional presence of CSCs by assaying for in vivo tumor-seeding ability after drug treatment in vitro. In these experiments, NCI-H1299 cells were treated with drugs in vitro for 5 days, allowed to recover and expand in culture for at least 5 days in the absence of drug treatment, then injected in serial limiting dilutions into mice. At the same time, we tested these pretreated cells for ALDH activity, expression of stem cell transcription factors, and proliferation and migration capacity (Figure 4A). As shown in Figure 4B, DSF/Cu significantly decreased ALDH activity (0.3\%) relative 
A
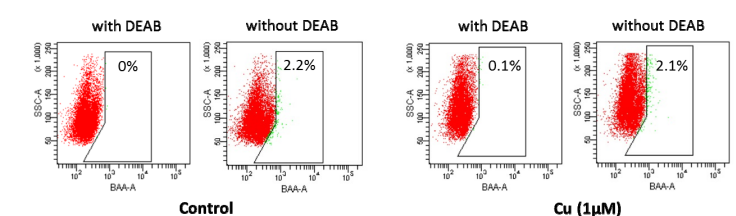

H1299
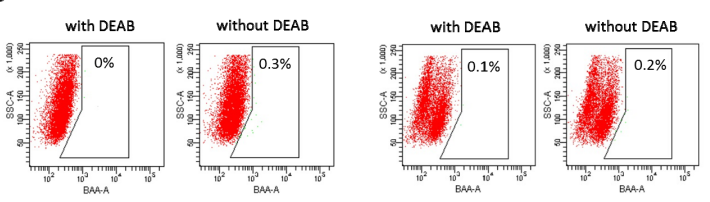

DSF $(0.5 \mu \mathrm{M})$

DSF/Cu $(0.5 / 1 \mu \mathrm{M})$
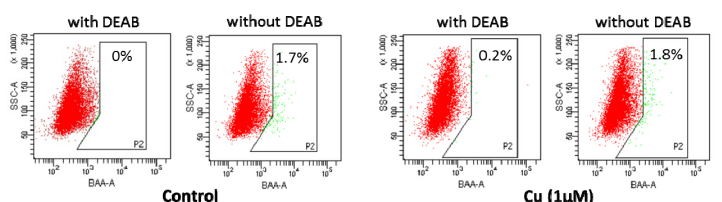

H460

Cu $(1 \mu \mathrm{M})$

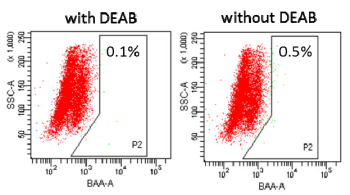

DSF (0.5 $\mu \mathrm{M})$
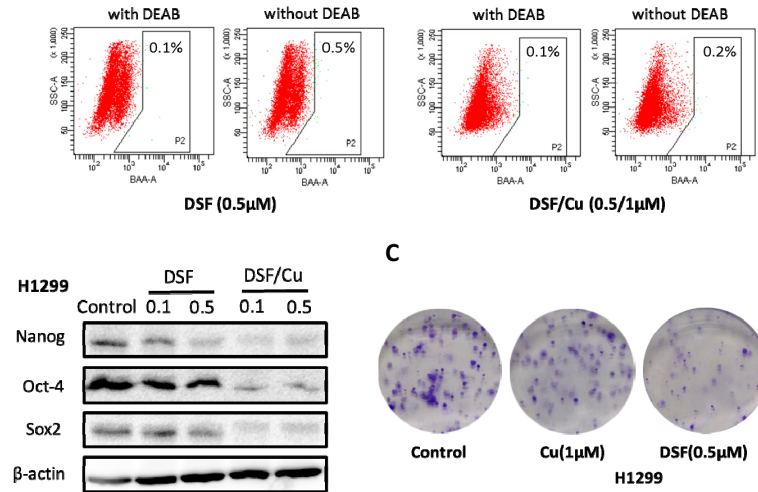

C

DSF/Cu $(0.5 / 1 \mu \mathrm{M})$
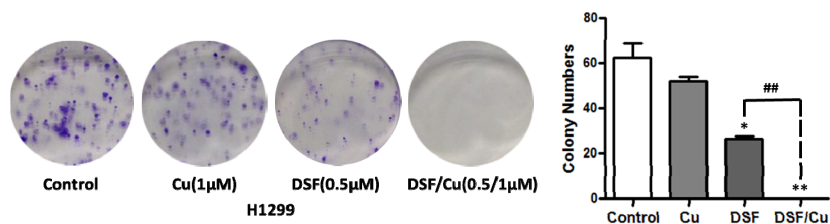

D
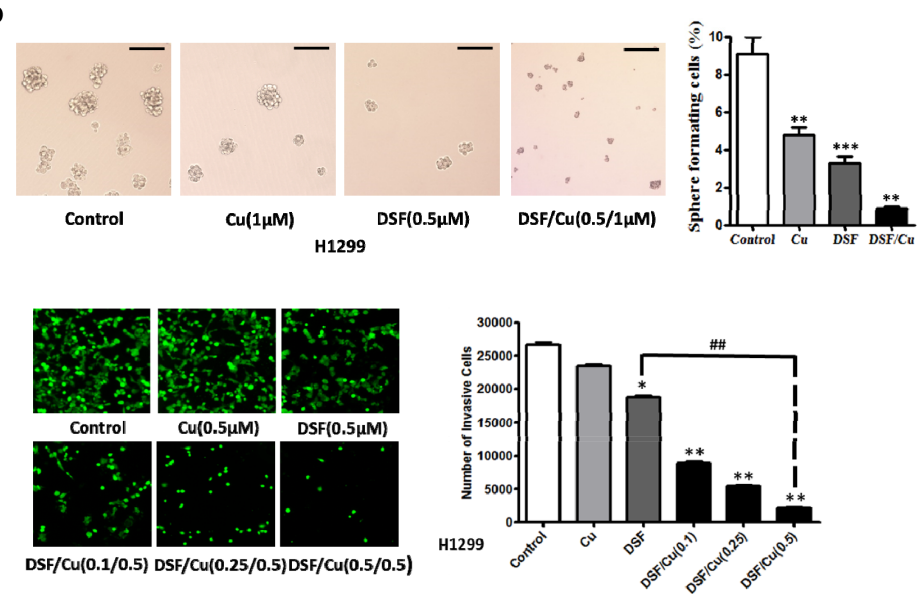

Figure 2: DSF/Cu inhibits the stemness of NSCLCs in vitro. A. Inhibitory effect of DSF $(0.5 \mu \mathrm{M}), \mathrm{Cu}(1 \mu \mathrm{M})$ and $\mathrm{DSF} / \mathrm{Cu}(0.5 / 1$ $\mu \mathrm{M})$ on the ALDH-positive cell population from the NSCLC cells lines H1299 and H460. B. DSF $(0.1 \mu \mathrm{M}$, and $0.5 \mu \mathrm{M})$ and DSF/Cu $(0.1 / 1 \mu \mathrm{M}$, and $0.5 / 1 \mu \mathrm{M})$ inhibit the expression of the stem cell transcription factors Nanog, Sox 2 and Oct-4 expression in H1299 cells. C. Inhibitory effect of DSF $(0.5 \mu \mathrm{M}), \mathrm{Cu}(1 \mu \mathrm{M})$ and DSF/Cu $(0.5 / 1 \mu \mathrm{M})$ on the colony forming ability of $\mathrm{H} 1299$ cells $\left(* P<0.05,{ }^{*} * P<\right.$ 0.01 , \#\#P<0.01, one-way ANOVA). D. Inhibitory effect of DSF and DSF/Cu on tumorsphere formation. Tumorspheres were incubated with DSF $(0.5 \mu \mathrm{M}), \mathrm{Cu}(1 \mu \mathrm{M})$ and $\mathrm{DSF} / \mathrm{Cu}(0.5 / 1 \mu \mathrm{M})$ for 7 days. Scale bar, $100 \mu \mathrm{m}$. $\left(* * P<0.01,{ }^{* * *} P<0.001\right.$, one-way ANOVA). E. Inhibitory effect of DSF/Cu on transwell invasion assay. Cells were incubated with DSF $(0.5 \mu \mathrm{M}), \mathrm{Cu}(0.5 \mu \mathrm{M})$ and DSF/Cu $(0.1 / 0.5 \mu \mathrm{M}$, $0.25 / 0.5 \mu \mathrm{M}$ and $0.5 / 0.5 \mu \mathrm{M})$ in transwells for 24 hours $\left(* P<0.05,{ }^{* *} P<0.01\right.$, one-way ANOVA). 
to the DMSO control $(2.0 \%)$, but paclitaxel $(2.3 \%)$ and DSF alone (3.2\%) treatment slightly increased the ALDH activity in pretreated cells. These results suggest that in the groups pretreated with paclitaxel and DSF alone, the expansion of ALDH-positive CSCs increased during the recovery process. As shown in Figure 4C, $\mathrm{DSF} / \mathrm{Cu}$ pretreatment resulted in a $>40$-fold decrease in sphere-forming ability relative to control or paclitaxel pretreatment. Similarly, DSF/Cu pretreatment inhibited the expression of the stem cell transcription factors Sox2 and Nanog more strongly than DSF alone or paclitaxel (Figure 4D). There was no obvious inhibition of Oct-4 expression. As shown in Figure 4E, paclitaxel, DSF and $\mathrm{DSF} / \mathrm{Cu}$ pretreatments all inhibited the migratory capacity of the cells, but $\mathrm{DSF} / \mathrm{Cu}$ pretreatment had enhanced inhibitory efficacy relative to pretreatment with paclitaxel and DSF alone. Taken together, our results show that in pretreatment experiments, $\mathrm{DSF} / \mathrm{Cu}$ significantly inhibited the stemness of NCI-H1299 cells in vitro.

We also observed that $\mathrm{DSF} / \mathrm{Cu}$ pretreatment of NCI-H1299 cells resulted in a dramatic decrease in tumor seeding relative to cells pretreated with DMSO (control), paclitaxel and DSF alone (Figure 4F and Table 1). The

A

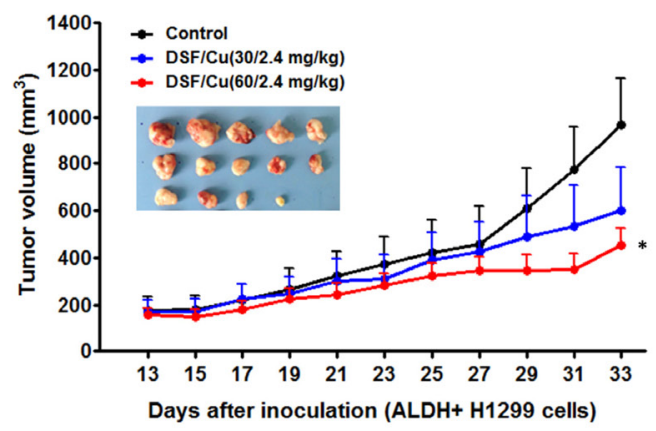

C

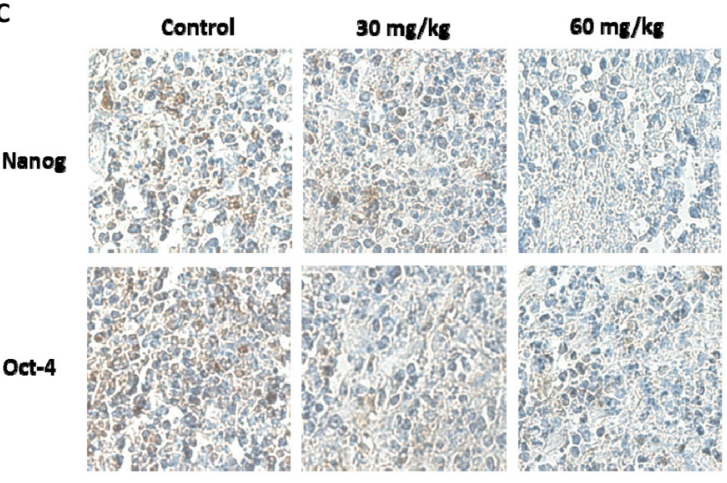

tumor incidence and latency period in mice receiving $\mathrm{DSF} / \mathrm{Cu}$-pretreated cells showed clear distinctions relative to mice receiving cells pretreated with DMSO, paclitaxel or DSF alone (Table 1). These findings confirmed that ALDH-positive CSCs within NSCLCs are resistant to paclitaxel and DSF alone, but are sensitive to DSF/Cu. Treatment with the DSF/Cu complex may be a potential strategy to inhibit NSCLC recurrence driven by ALDHpositive CSCs.

\section{Effects of DSF/Cu treatment in vivo and tumor regrowth on secondary xenografts}

To determine whether DSF/Cu can target ALDHpositive cells and inhibit tumor growth and recurrence in vivo, we used a secondary xenograft model of NCI-H1299 cells in NOD/SCID mice (Figure 5A). Three groups of mice $(\mathrm{NaCl}$ solution control, DSF $60 \mathrm{mg} / \mathrm{kg}$ and DSF/Cu $60 / 2.4 \mathrm{mg} / \mathrm{kg}$; eight mice in each group) were implanted with tumor cells. The animals were intravenously injected with $0.9 \% \mathrm{NaCl}$ solution, DSF (DSF-loaded lipid emulsion) or $\mathrm{DSF} / \mathrm{Cu}(\mathrm{Cu}$, intragastric administration) every two days. After 2 weeks of treatment, the volumes
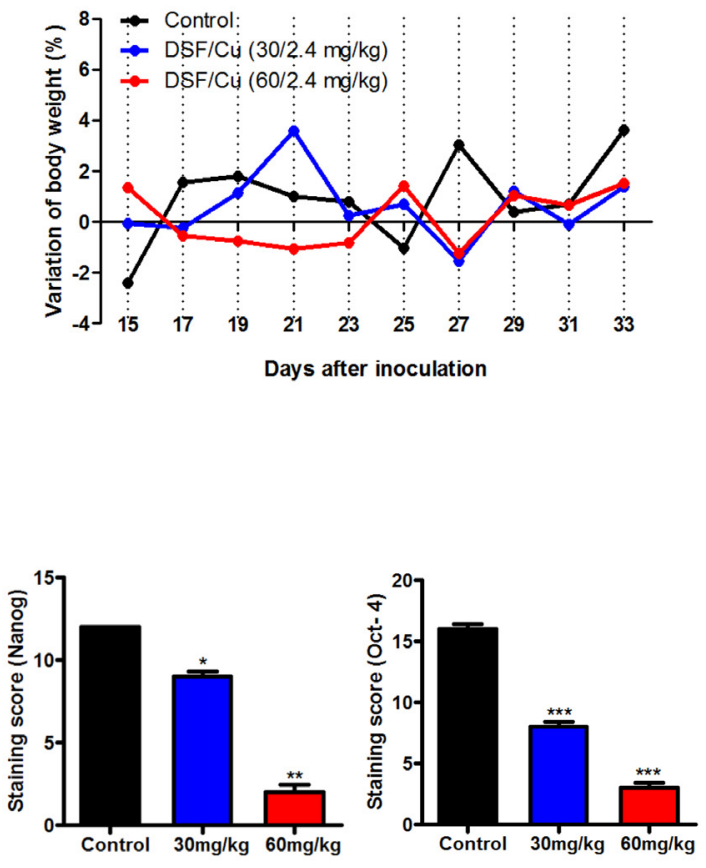

Figure 3: DSF/Cu inhibits ALDH-positive NSCLC stem cells in vivo. A. DSF/Cu decreases the size of tumors derived from ALDH-positive NSCLC xenografts. Images of the tumors that developed in NOD/SCID mice from each treatment group are also shown. ( ${ }^{*} P<0.05$, one-way ANOVA). B. DSF/Cu has no apparent toxicity as determined by body weight. C. Representative images of immunohistochemical staining of tumor tissue for the stem cell transcription factors Nanog and Oct-4. The staining intensity was scored as 0 (negative), 1 (weak), 2 (medium) and 3 (strong). Extent of staining was scored as $0(0 \%), 1(1-25 \%), 2(26-50 \%), 3(51-75 \%)$ and 4 (76-100\%), according to the percentage of the positively stained areas in relation to the whole carcinoma area $(* P<0.05, * * P<0.01, * * * P$ $<0.001$, one-way ANOVA). 
of all the primary xenograft tumors in the DSF/Cu and DSF treatment groups were significantly smaller than those in control animals (Figure 5B). However, the ability of residual cancer cells to initiate tumors upon reimplantation in secondary mice is a more definitive assay, so we examined the growth of secondary tumors

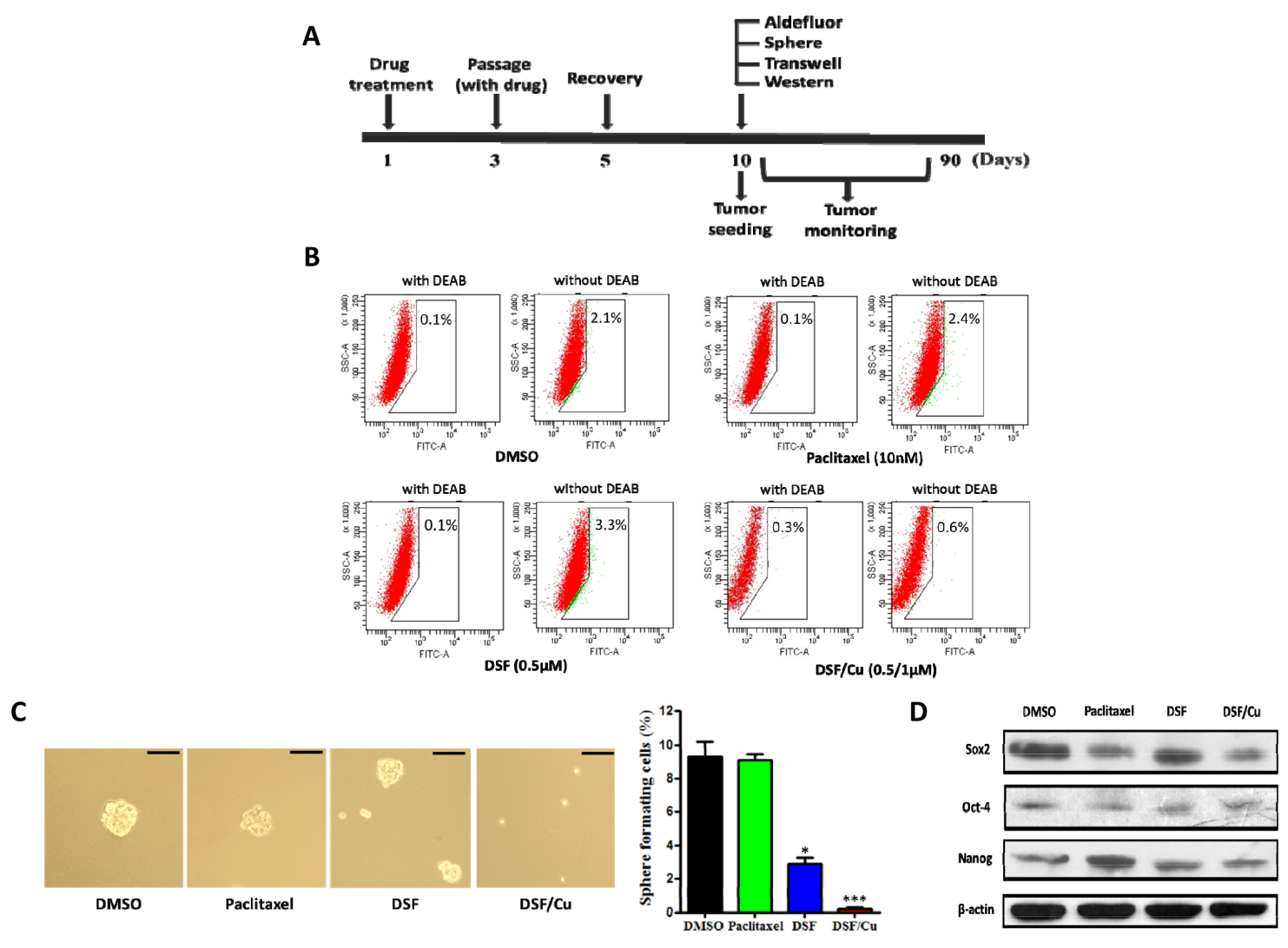

E

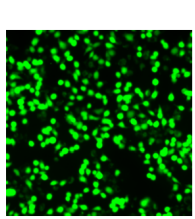

Control

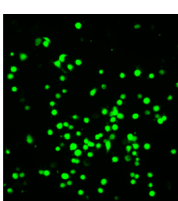

Paclitaxel

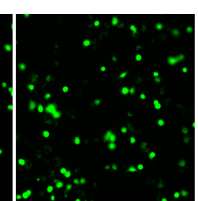

DSF

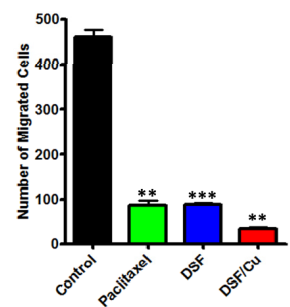

$\mathbf{F}$

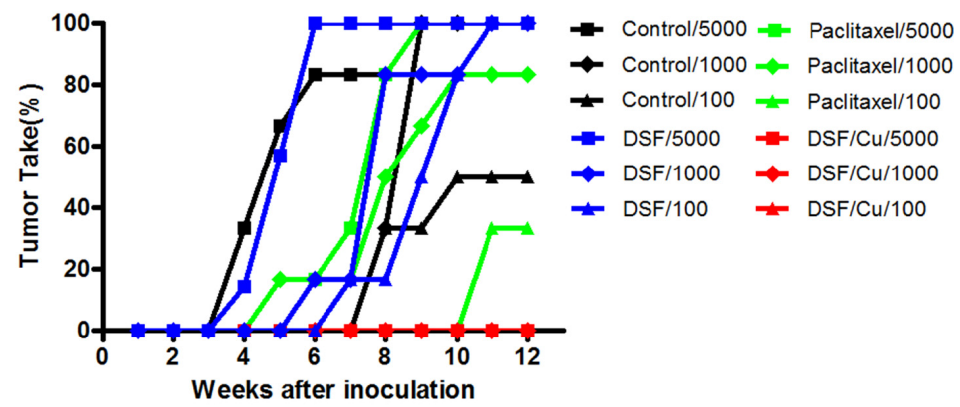

Figure 4: Effects of DSF/Cu pretreatment on NSCLC stem cell numbers in vitro and tumor seeding in vivo. A. Schematic representation of treatment scheme. Cells were pretreated with drugs, then allowed to recover before experimental testing. B. Inhibitory effect of drug pretreatment on ALDH-positive cell populations before inoculation. C. Inhibitory effect of drug pretreatment on tumorsphere formation. Scale bar, $50 \mu \mathrm{m}$. ( ${ }^{*} P<0.05, * * * P<0.001, \chi^{2}$ test). D. Inhibitory effect of drug pretreatment on the expression of stem cell transcription factors. E. Inhibitory effect of drug treatment on transwell migration assays $(* * P<0.01, * * * P<0.001$, one-way ANOVA). F. Latency periods and tumor take percentage in xenograft mice receiving cells pretreated with the indicated drugs. 
Table 1: Tumor incidence and latency period in xenograft mice receiving cells pretreated with different drugs

\begin{tabular}{lccc}
\hline Group & Cells injected & Tumor incidence & Latency period(days) \\
\hline Control & 5000 & $6 / 6(100.0 \%)$ & 35 \\
& 1000 & $6 / 6(100.0 \%)$ & 57 \\
& 100 & $3 / 6(50.0 \%)$ & 56 \\
Paclitaxel & 5000 & $6 / 6(100.0 \%)$ & 48 \\
& 1000 & $5 / 6(83.3 \%)$ & 52 \\
& 100 & $2 / 6(33.3 \%)$ & 72 \\
DSF & 5000 & $7 / 7(100.0 \%)$ & 33 \\
& 1000 & $6 / 6(100.0 \%)$ & 54 \\
& 100 & $6 / 6(100.0 \%)$ & 62 \\
DSF/Cu & 5000 & $1 / 6(16.7 \%)$ & 88 \\
& 1000 & $0 / 7(0.0 \%)$ & - \\
\end{tabular}

in NOD/SCID mice inoculated with primary tumor cells obtained from the primary xenografts. The results showed that cancer cells from control and DSF-treated animals exhibited rapid tumor regrowth and a higher tumor take percentage. However, the cancer cells obtained from $\mathrm{DSF} / \mathrm{Cu}$-treated mice largely failed to produce any tumors in the recipient mice up to 8 weeks after implantation (Figure 5C and Table 2). By day 67, tumor cells derived from DSF/Cu-treated mice only caused two tumors out of eight inoculations, whereas the other tumor cells yielded tumors as early as days 42 to 54 (Table 2). At the end of the experimental period ( 13 weeks), tumors were isolated from the animals and the tumor cells were analyzed by Aldefluor assay. As shown in Figure 5D, DSF/Cu reduced the ALDH-positive population to $0 \%$.

As shown in Figure 5C, the residual cancer cells from animals treated with DSF alone exhibited more rapid tumor regrowth and a higher tumor take percentage than the control group. A reasonable explanation for this is that DSF inhibited non-CSCs in the primary tumors, which may increase the proportion of CSCs in the residual cancer cells. After inoculating the same number of residual cancer cells into the secondary mice, it would therefore be expected that the DSF group would exhibit more rapid tumor regrowth and a higher tumor take percentage than the control group.

These results suggest that $\mathrm{DSF} / \mathrm{Cu}$ is able to eliminate ALDH-positive NSCLC stem cells in primary xenografts, thereby abrogating the regrowth of tumors in secondary mice. Taken together with the in vivo Aldefluor assay results, these findings suggest that the $\mathrm{DSF} / \mathrm{Cu}$ complex, rather than DSF alone, targets ALDH-positive NSCLC stem cells with high potency and inhibits tumor recurrence in vivo.

\section{ALDH1A1 plays a key role in the $\mathrm{DSF} / \mathrm{Cu}$ - induced elimination of cancer stem cells}

Recent evidence suggests that ALDH1 or ALDH3A1, which may be lung tumor stem cell markers or therapeutic targets, are highly expressed in some NSCLC cell lines as well as in patient lung cancer samples $[21,22]$. However, the stem cell-related function and significance of the ALDHs have not yet been thoroughly investigated in NSCLCs. Therefore, we firstly examined the inhibitory effects of DSF, $\mathrm{Cu}$ and DSF/Cu treatment on the expression of three ALDH isozymes, ALDH1A1, ALDH1A3 and ALDH3A1. As shown in Figure 6A, DSF/ $\mathrm{Cu}$ dramatically reduced the expression of all three ALDH isozymes in a concentration-dependent manner, and DSF/ $\mathrm{Cu}$ was far more potent than DSF alone.

To explore the role of ALDH isozymes in ALDHpositive NSCLC stem cells and the mechanism underlying the activity of DSF/Cu, we used specific siRNAs to silence ALDH1A1, ALDH1A3 and ALDH3A1 in NCI-H1299 cells. We examined the effects of siRNA knockdown of ALDH isozymes on the capacity of the cells for selfrenewal, the expression of stem cell transcription factors, and ALDH activity. Cells transfected with scramble siRNA were used as controls. The levels of ALDH isozymes in siRNA-treated cells were reduced by more than $70 \%$ compared with control cells (Supplemental Figure S8). We assessed the effects of knockdown of ALDH isozymes on colony-forming efficiency. As shown in Figure 6B, the colony numbers were significantly reduced by knockdown of ALDH1A1, but not of ALDH1A3 or ALDH3A1. This result suggests that ALDH1A1 predominantly contributed to the colony-forming capacity. Moreover, we assessed the expression of stem cell transcription factors in ALDH1A1, 
ALDH1A3 and ALDH3A1 knockdown cells. As shown in Figure 6C, the expression of Nanog, Oct-4 and Sox 2 was more strongly reduced in ALDH1A1 knockdown cells than in ALDH1A3 or ALDH3A1 knockdown cells, suggesting that ALDH1A1 plays a key role in maintaining the stemness of NCI-H1299 cells. Furthermore, we examined the ALDH levels in siRNA-treated cells by Aldefluor assays, and found that ALDH1A1 and ALDH1A3 contribute to functional ALDH activity (Figure 6D). These results suggest that ALDH activity is associated with ALDH1A1 and ALDH1A3 expression, yet only ALDH1A1 plays a key role in maintaining ALDHpositive stem cells in NCI-H1299 cells.

To further evaluate whether ALDH1A1 is the target of the $\mathrm{DSF} / \mathrm{Cu}$ complex, plasmids expressing human ALDH isozymes were transfected into
NCI-H1299 cells. As shown in Figure 6E, ALDH1A1overexpressing cells exhibited stronger colony-forming efficiency than normal NCI-H1299 cells. Interestingly, ALDH1A3- and ALDH3A1-overexpressing cells had lower colony-forming efficiency than control NCI-H1299 cells. Moreover, DSF and DSF/Cu both significantly inhibited the colony-forming capacity of ALDH1A1-overexpressing cells (Figure 6E). The inhibitory efficacy of DSF/Cu complex appeared to be stronger than that of DSF alone, but the difference was not statistically significant (Figure 6E).

Taken together, these results show that ALDH1A1, which plays a key role in maintaining ALDH-positive NSCLC stem cells, may be the target of the DSF/Cu complex.
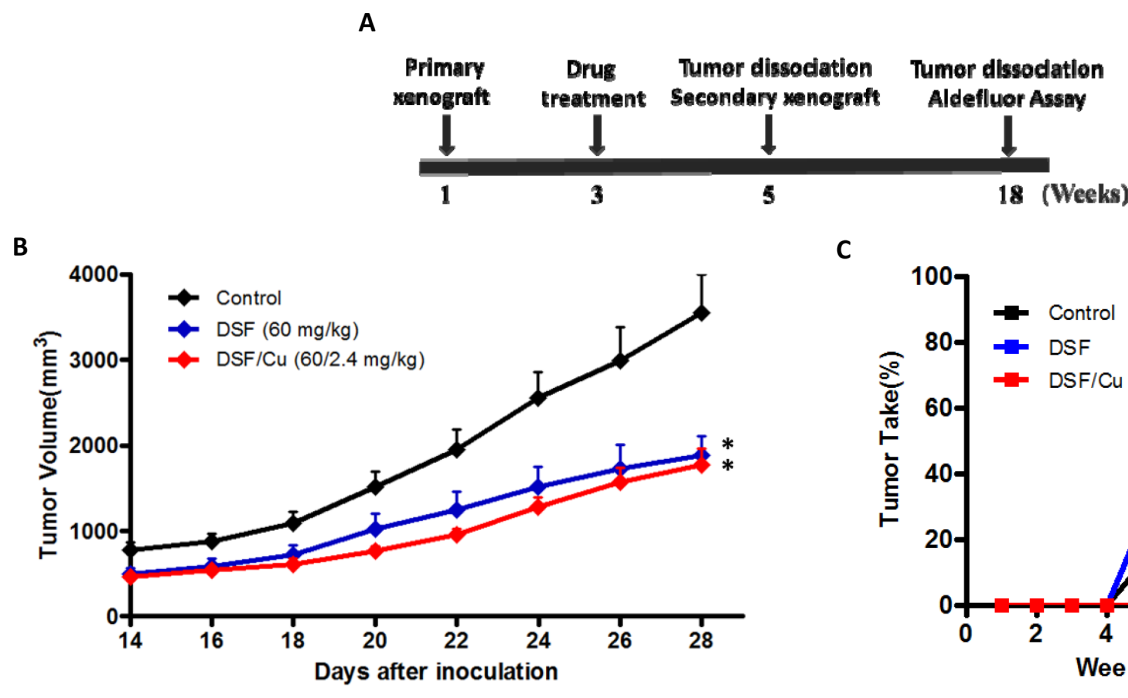

C

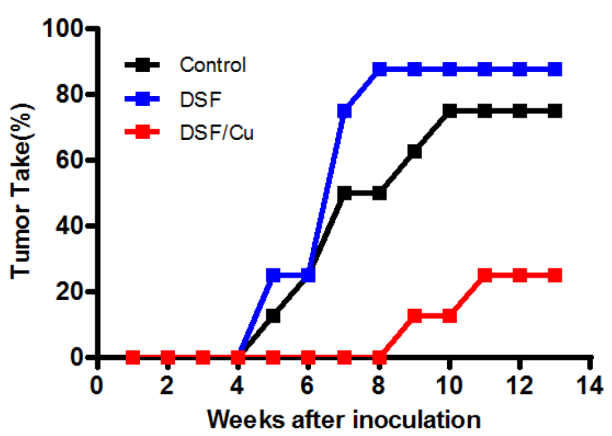

D
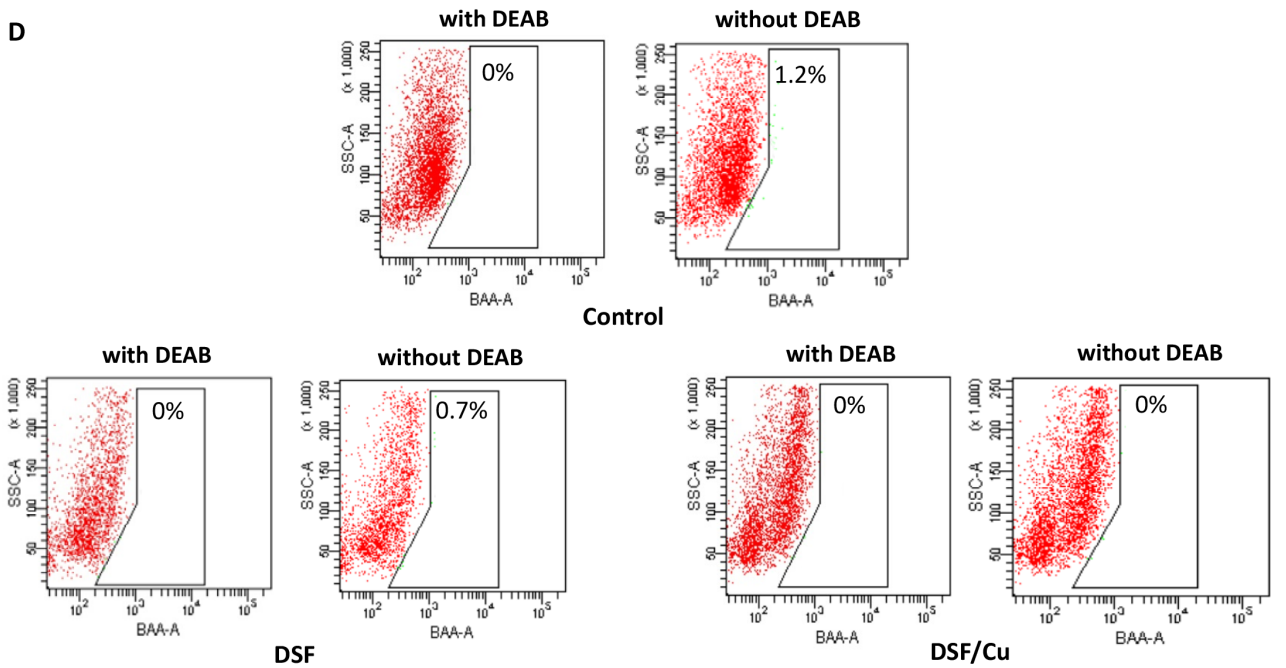

Figure 5: Effects of DSF and DSF/Cu treatment in vivo and tumor growth on secondary xenografts. A. Schematic representation of the treatment scheme. B. Drug treatment reduces the size of primary xenograft tumors $(* P<0.05,2$-tailed $t$ test). C. Percentage of tumor take and latency period in mice receiving secondary xenografts from each treatment group. D. Percentage of ALDHpositive cells in secondary xenograft tumors from each treatment group. 
Table 2: Tumor incidence and latency period in mice receiving secondary xenografts

\begin{tabular}{lccc}
\hline Group & Cells injected & Tumor incidence & Latency period(days) \\
\hline Control & 5000 & $6 / 8(75.0 \%)$ & 48 \\
$\mathrm{DSF} / 5000$ & 5000 & $7 / 8(87.5 \%)$ & 42 \\
$\mathrm{DSF} / \mathrm{Cu} / 5000$ & 5000 & $2 / 8(25.0 \%)$ & 67 \\
\hline
\end{tabular}

\section{DISCUSSION}

The anticancer efficacy of DSF, a clinically used anti-alcoholism drug, has been evaluated in various cancers [23-26]. DSF also enhances the cytotoxicity of several anticancer drugs as well as radiotherapy, suggesting that it is a potential chemotherapeutic agent [34]. An initial assessment of the effect of adding DSF to standard chemotherapy in lung cancer has recently been completed (NCT 00312819). The results showed that there was an increase in survival in the experimental group. Other Phase I/II clinical trials of DSF in melanoma and liver metastases (NCT00256230 and NCT00742911) are ongoing. However, the effect of $\mathrm{DSF} / \mathrm{Cu}$ treatment in CSCs and its role as an irreversible inhibitor of ALDHs has not been thoroughly studied. Therefore, in the present study, both in vitro and in vivo systems were used to determine whether DSF acts against ALDH-positive NSCLC stem cells.

Previous reports have indicated that the anticancer activity of DSF is dependent on copper [26, 28-30]. Our data showed that CSCs within NSCLCs are resistant to paclitaxel and DSF alone but are sensitive to DSF/Cu (Figure 4-5). In other words, copper is critical for DSFinduced cytotoxicity in NSCLC stem cells. Mechanisms of copper-induced cytotoxicity are still poorly defined. It has been reported that bioavailable copper levels modulate tumor growth. Serum copper levels are elevated in cancer patients and copper-chelating drugs have antiangiogenic activity in animal models $[35,36]$. Copper binding agents, which act as copper ionophores, lead to caspase inhibition and paraptotic cell death in human cancer cells [29]. DSF, as a bivalent metal ion chelator, forms a complex with copper and has enhanced cytotoxicity. In addition, DSF has low chemical stability in physiological environments [37]. The DSF/Cu complex may also improve the transport of DSF into cancer cells.

To explore whether the DSF/Cu complex may have an inhibitory effect on growth factor receptors mediating the expansion of CSCs, we tested the inhibitory effects of DSF and $\mathrm{DSF} / \mathrm{Cu}$ treatment on the expression of EGFR, FGFR1 and IGF-1R $\beta$ in both H1299 and A549 cells (Supplemental Figure S9). In the H1299 cell line, which contains ALDH-positive NSCLC stem cells, DSF $(0.5 \mu \mathrm{M})$ and $\mathrm{DSF} / \mathrm{Cu}(0.5 / 1 \mu \mathrm{M})$ greatly reduced the expression of EGFR, FGFR1 and IGF-1R $\beta$. The inhibitory effect of the $\mathrm{DSF} / \mathrm{Cu}$ complex was stronger than that of
DSF alone. However, in the A549 cell line, which does not contain ALDH-positive NSCLC stem cells, DSF/Cu decreased the protein levels of FGFR1 but not EGFR or IGF-1R $\beta$. These results suggest that by inhibiting ALDH, $\mathrm{DSF}$ and DSF/Cu may have an inhibitory effect on the expression of growth factor receptors that mediate the expansion of ALDH-positive CSCs.

In some cases, it has proved difficult to confirm markers that originally appeared to robustly distinguish tumorigenic from nontumorigenic cells [38]. Thus, it is necessary to identify markers that reproducibly distinguish tumorigenic and nontumorigenic cells, at least in specific subsets of experimental cell resources. Therefore, we used a serial implantation mouse model to investigate possible differences in the tumor formation potential of sorted ALDH-positive and ALDH-negative cells, which is the gold standard for determining CSCs (Figure 1). Our data support the hypothesis that ALDH may be a single CSC marker in some NSCLCs, regardless of the presence of other reported lung CSC markers, such as CD133, CD44 and so on. Nevertheless, the human ALDH superfamily comprises 19 isozymes and the different isozymes may possess multiple different catalytic and noncatalytic functions. Our data showed that only ALDH1A1 plays a key role in ALDH-positive NSCLC stem cells, suggesting that ALDH1A1 could be a potential target in clinical treatment (Figure 6).

Cancer stem cell theory partially explains tumor recurrence, drug resistance, and tumor metastasis. The emerging evidence linking stemness to poor prognosis and therapy failure suggests that therapeutic targeting of determinants of stemness might be an effective means to eradicate CSCs and prevent recurrence [39]. Thus, we used two NOD/SCID xenograft models to determine whether DSF/Cu can target ALDH-positive NSCLC stem cells and inhibit tumor recurrence in vivo, as assessed by tumor growth in recipient mice that were inoculated with tumor cells derived from DSF/Cu-treated cell lines or primary xenografts. The results showed that $\mathrm{DSF} / \mathrm{Cu}$ complex treatment was able to target ALDH-positive NSCLC stem cells and inhibit tumor recurrence (Figures 4-5). We also observed that DSF/Cu pretreatment of $\mathrm{H} 1299$ cells resulted in a dramatic decrease in tumor-seeding ability relative to pretreatment with DMSO (control), paclitaxel and DSF alone (Figure 4F). These findings indicate that CSCs within NSCLC cell lines are resistant to paclitaxel and DSF alone but are sensitive to treatment with $\mathrm{DSF} / \mathrm{Cu}$. 
A

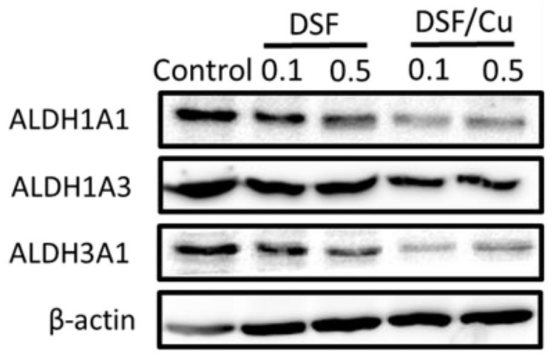

B
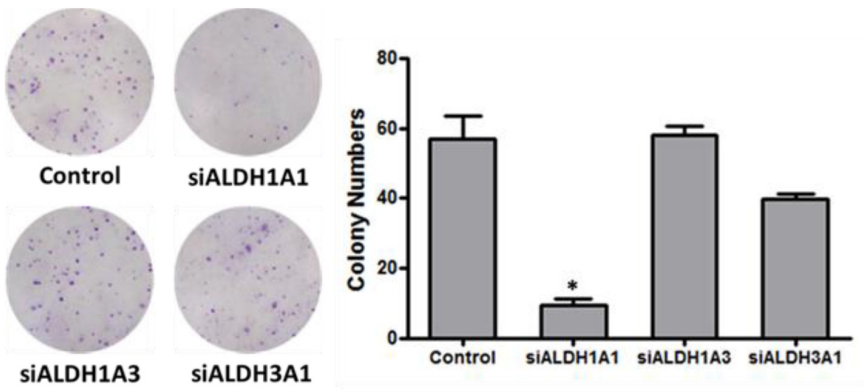

C
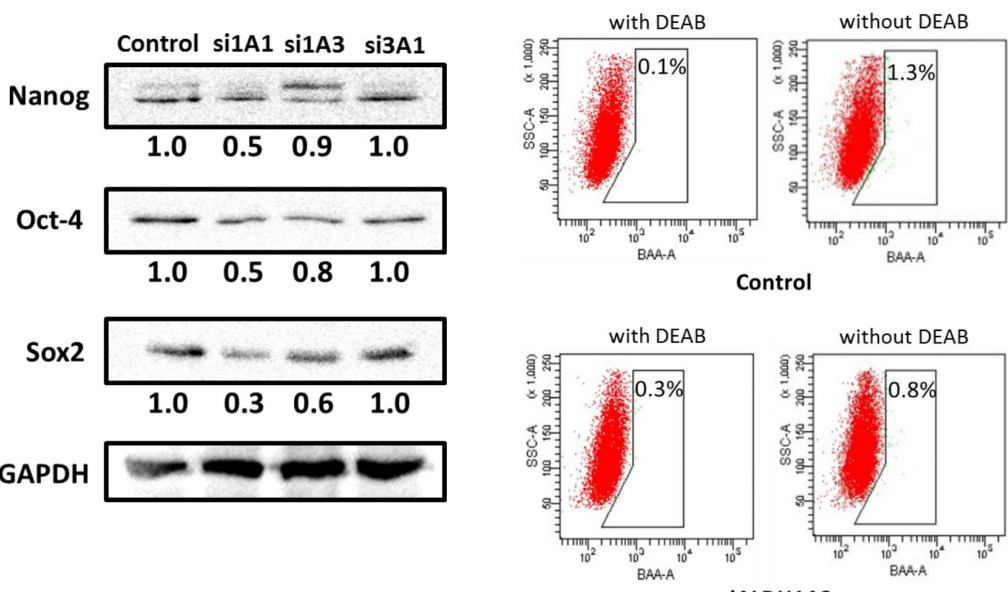

SIALDH1A3
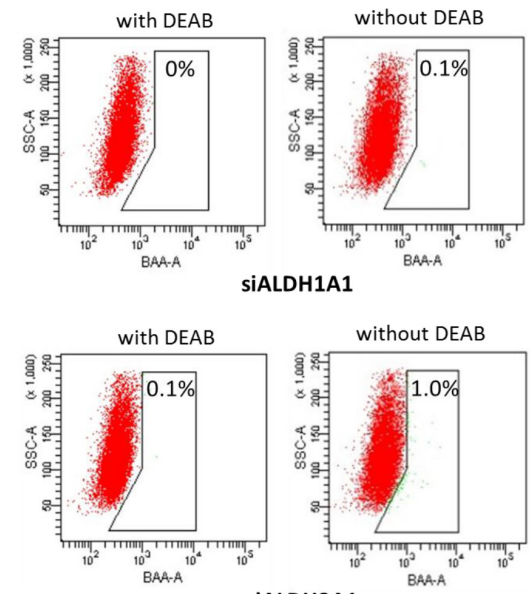

SIALDH3A1

E
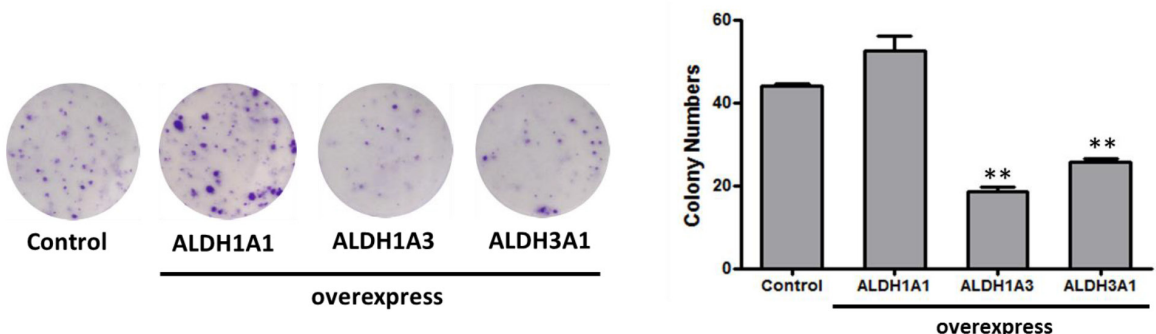

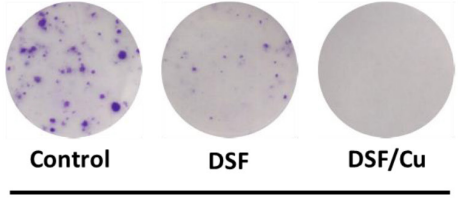

ALDH1A1 overexpress

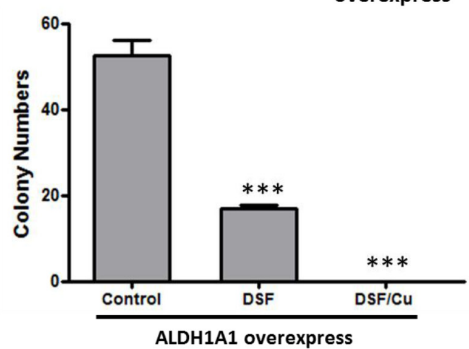

Figure 6: ALDH1A1 plays a key role in ALDH-positive NSCLC stem cells. A. DSF $(0.1 \mu \mathrm{M}$, and $0.5 \mu \mathrm{M})$ and DSF/Cu $(0.1 / 1$ $\mu \mathrm{M}$, and $0.5 / 1 \mu \mathrm{M})$ inhibits the expression of the ALDH isozymes ALDH1A1, ALDH1A3 and ALDH3A1. B. The effects of siRNA knockdown of ALDH isozymes on colony-forming efficiency ( ${ }^{*} P<0.05$, one-way ANOVA). C. The levels of stem cell transcription factors in siRNA-treated cells. D. ALDH activity in siRNA-treated cells. E. Top row: the effects of overexpression of ALDH isozymes on the colony-forming efficiency of NCI-H1299 cells; bottom row: the inhibitory effects of DSF $(0.5 \mu \mathrm{M})$ and DSF/Cu $(0.5 / 1 \mu \mathrm{M})$ on ALDH1A1-overexpressing NCI-H1299 cells $(* * P<0.01, * * * P<0.001$, one-way ANOVA). 
In conclusion, we have shown that DSF/copper can inhibit ALDH-positive NSCLC stem cells in vitro and in vivo. These findings provide a strong rationale for clinical evaluation of the DSF/copper complex for lung cancer therapy.

\section{MATERIALS AND METHODS}

\section{Cell lines and reagents}

Human NSCLC cell lines (NCI-H460, NCI-H1299, NCI-H522 and A549) were obtained from the American Type Culture Collection. Authentication of these cell lines included morphology analysis, growth curve analysis and short tandem repeat analysis. Cells were routinely cultured in Roswell Park Memorial Institute 1640 medium supplemented with $10 \%$ fetal bovine serum (FBS) and maintained at $37{ }^{\circ} \mathrm{C}$ in a humidified incubator with $5 \%$ $\mathrm{CO} 2$.

Disulfiram and Copper(II) D-gluconate were purchased from Sigma-Aldrich (St. Louis, MO, USA). The Disulfiram-loaded lipid emulsion was provided by Prof X Tang (Shenyang Pharmaceutical University, China). The drug loading content of the Disulfiramloaded lipid emulsion was $3 \mathrm{mg} / \mathrm{ml}$. The cumulative release of DSF from the lipid emulsion in $120 \mathrm{~h}$ was more than $60 \%$. A pharmacokinetic study of DSF in rat plasma after intravenous administration of a dose of 36 $\mathrm{mg} / \mathrm{kg}$ was carried out $\left(\mathrm{t}_{1 / 2}=0.1 \mathrm{~h}\right.$ and $\left.\mathrm{t}_{1 / 2 \mathrm{~d}}=0.3 \mathrm{~h}\right)$. The biological activity of the DSF-loaded lipid emulsion and conventional DSF has been compared previously [40].

The primary antibodies against Sox2, Oct- 4 and Nanog were purchased from Cell Signaling Technology. Antibody to CD133/2 was purchased from Miltenyi Biotec. Antibodies to $\beta$-actin and GAPDH were obtained from Santa Cruz Biotechnology. Antibodies to ALDH1A1, ALDH1A3 and ALDH3A1 were obtained from Novus Biologicals. ALDH isozymes siRNA and Lipofectamine were obtained from Life Technologies. Human ALDH cDNA clone were obtained from Sino Biological Inc.

\section{Aldefluor assay and cell sorting}

A cell population with a high ALDH enzyme activity was previously reported to be enriched in lung stem/ progenitor cells [41]. Aldefluor assays were performed according to the manufacturer's guidelines (Stem Cell Technologies). Single cells obtained from cell cultures or xenograft tumors were incubated in Aldefluor assay buffer containing an ALDH substrate, bodipy-aminoacetaldehyde $\left(1 \mu \mathrm{mol} / 1 \mathrm{per} 1,000,000\right.$ cells), for 30 to $60 \mathrm{~min}$ at $37^{\circ} \mathrm{C}$. As a negative control, a fraction of the cells from each sample was incubated under identical conditions in the presence of the ALDH inhibitor diethylaminobenzaldehyde (DEAB). Flow cytometry was used to measure the ALDH-positive cell population. Desired cell populations were isolated using a FACSAriaIII flow cytometer (BD Biosciences).

\section{Colony forming assay}

Cells were plated in $35-\mathrm{mm}$ dishes at 300 cells/ well and treated with different concentrations of drugs. Then the cells were incubated for an additional 7 to 12 days. Treatments were carried out in triplicate. The colonies obtained were fixed in formalin and stained with hematoxylin. The colonies were counted and compared with untreated cells.

\section{Tumorsphere formation assay}

Single cells prepared from mechanical and enzymatic dissociation were seeded in 6-well ultra-low attachment plates (Corning, NY) at 3000 cells/well and cultured for about 2 weeks in serum-free DMEM/F-12 medium with B27 supplement (1×, Invitrogen), $20 \mathrm{ng} /$ $\mathrm{ml}$ human recombinant bFGF (PeproTech), $20 \mathrm{ng} / \mathrm{ml}$ EGF (PeproTech), $10 \mathrm{ng} / \mathrm{ml}$ leukemia inhibitory factor (Chemicon) and $4 \mathrm{U} / 1$ insulin (Sigma).

\section{Western blotting analysis}

Tumor tissue proteins were purified according to the reported method [42]. Equal amounts of total protein extracts from cultured cells or tissues were fractionated by $10-15 \%$ SDS-PAGE and electrically transferred onto polyvinylidene difluoride membranes (Bio-Rad, Richmond, CA). Mouse or rabbit primary antibodies and horseradish peroxidase (HRP)-conjugated appropriate secondary antibodies were used to detect the designated proteins. The bound secondary antibodies on the PVDF membrane were reacted with ECL detection reagents (Thermo Scientific) and exposed using an ImageQuant LAS 4000 mini system (GE Healthcare, Buckinghamshire, UK).

\section{Transwell invasion assay}

Cellular potential for invasiveness was determined using Matrigel invasion chambers (BD Biosciences) according to the manufacturer's instruction. Briefly, cells were seeded into the upper chambers at $2 \times 10^{5}$ per chamber in serum-free medium. The outer chambers were filled with the same medium but containing fetal bovine serum as the chemoattractant. Cells were incubated at $37^{\circ} \mathrm{C}$ for $24 \mathrm{~h}$, and the non-invading cells were removed by swabbing the top layer of the Matrigel. The cells were fixed and stained with Calcein-AM (Sigma-Aldrich). Chemotaxis was quantified with a high content drug screening system ImageXpressR Micro (Molecular Devices) by counting cells that had migrated to the lower side of the filter. 


\section{Animal experiments}

For in vivo identification of ALDH-positive NSCLC stem cells, ALDH-positive and ALDH-negative H1299 cells were sorted out by FACS and resuspended in 200 $\mu \mathrm{l}$ 1:1 Matrigel:DMEM solution. Non-obese diabetic/severe combined immunodeficiency (NOD/ SCID) mice were then inoculated with 5000 ALDHpositive cells in one flank and 5,000 ALDH-negative cells in the other flank. Tumor growth was allowed to proceed for 7 weeks and then the animals were humanely euthanized. Disassociated cells were obtained from the tumors and then were reanalyzed using the Aldefluor assay and sorted by FACS. Living cells from the dissociated tumors were sorted out by FACS for secondary xenografts. 500 or 5,000 ALDH-positive and ALDH-negative cells were inoculated in opposite sides of each NOD/SCID mouse. The growth of tumors was monitored and tumor volumes were measured every other day. Tumor volume was measured according to the equation: tumor volume $=(\pi / 6) \times\left(\mathrm{L} \times \mathrm{W}^{2}\right)$, where $\mathrm{L}$ and $\mathrm{W}$ are the longer and shorter dimensions of the tumor. Mice were humanely euthanized when the larger one of the two tumors reached 800 to $1,000 \mathrm{~mm}^{3}$.

For in vivo drug treatment studies, ALDH-positive H1299 cells were sorted and resuspended in $200 \mu \mathrm{l}$ 1:1 Matrigel:DMEM solution, then 5,000 cells were inoculated into NOD/SCID mice. Two weeks after cell inoculation, animals were injected with $\mathrm{DSF} / \mathrm{Cu}(30 \mathrm{mg} /$ $\mathrm{kg}$ and $60 \mathrm{mg} / \mathrm{kg}$ ) every other day for 5 weeks.

For drug pretreatment experiments, parental H1299 cells were treated with DMSO, paclitaxel (10 nM), DSF $(0.5 \mu \mathrm{M})$ and $\mathrm{DSF} / \mathrm{Cu}(0.5 / 1 \mu \mathrm{M})$ for 5 days and allowed to recover in the absence of drug for at least 5 days prior to injection in vivo. Cells from different groups were serially diluted $\left(5 \times 10^{3}, 10^{3}\right.$ and $\left.10^{2}\right)$ and then injected into NOD/ SCID mice. Tumor incidence was monitored for 90 days after injection.

For in vivo drug treatment and secondary xenografts, $1 \times 10^{6} \mathrm{H} 1299$ cells were injected into NOD/SCID mice. Drug treatment (DSF $60 \mathrm{mg} / \mathrm{kg}$, DSF $/ \mathrm{Cu} 60 / 2.4 \mathrm{mg} / \mathrm{kg}$ ) was initiated two weeks after injection. After two weeks of treatment, tumors were dissociated to a single-cell suspension for secondary xenografts. $5 \times 10^{3}$ cells from each different group were inoculated into NOD/SCID mice. Tumor incidence was monitored for 90 days after injection.

Animal information: male, 18-22g, 4-5 week-old, NOD/SCID mice. This study was performed in strict accordance with the recommendations in the Guide for the Care and Use of Laboratory Animals of the National Institutes of Health. The protocol was approved by the Committee on the Ethics of Animal Experiments of Shenyang Pharmaceutical University.

\section{Dissociation of tumors}

Mice were humanely euthanized and tumors were harvested. Tumor tissues were dissociated mechanically and enzymatically to obtain a single-cell suspension as previously described [3]. Briefly, tumors were minced by cutting with a scalpel and incubated in DMEM medium mixed with collagenase/hyaluronidase (Stem Cell Technologies) at $37^{\circ} \mathrm{C}$ for 6 hours. The tissues were further dissociated with $0.25 \%$ trypsin (Hyclone), dispase and DNase (Stem Cell Technologies), and then passed through a $40-\mu \mathrm{m}$ nylon mesh to produce a single-cell suspension, which was used for Aldefluor assays and secondary xenografts.

\section{Immunohistochemistry}

Tissues embedded in paraffin were cut into $4 \mu \mathrm{m}$ thick sections, deparaffinized, and treated with citrate buffer. The sections were then blocked with avidin/ biotin for $20 \mathrm{~min}$. The slides were incubated with primary antibody overnight at $4^{\circ} \mathrm{C}$. Next, the slides were treated with secondary antibody with horseradish peroxidase goat anti-rabbit for $1-3 \mathrm{~h}$ and developed with 3, 3-diaminobenzidine (Sigma-Aldrich). Finally, the slides were counterstained with hematoxylin.

\section{RNA interference}

RNA interference of ALDH subfamilies was done using short interfering RNA (siRNA; Invitrogen). A nonspecific scramble siRNA was used as control. For transfection, cells were seeded in $60 \mathrm{~mm}$ dishes and allowed to attach overnight. Cells were transfected with siRNA (20 nmol/l) using Lipofectamine (Invitrogen) according to the manufacturer's recommendations. The efficiency of siRNA was confirmed by western blot. 24 hours after transfection, the cells were collected and processed for analysis of colony forming assay, FACS and immunoblotting as described above.

\section{Overexpression of ALDH isozymes}

Expression vectors were introduced into the NCI-H1299 cells by Sinofection (Sino Biological, Beijing, China). After 6 hours, the transfection mixture was removed and replaced by medium with serum. Colony forming assays were carried out after incubation for 72 hours. Cells were treated with DSF and DSF/Cu in the same manner as described above.

\section{Statistical analysis}

Statistical software SPSS17.0 was used for all analyses. Data are presented as means \pm standard error. 
Statistical differences were determined by two-tailed $t$-tests or by one-way analysis of variance for multiple comparisons. $P$ values were derived using $\chi^{2}$ tests when the data didn't obey normal distribution. $P$ values of $<0.05$ were considered statistically significant.

\section{CONFLICTS OF INTEREST}

No potential conflicts of interest were disclosed.

\section{GRANT SUPPORT}

The authors gratefully acknowledge financial support from the National Key Scientific Project for New Drug Discovery and Development (2013ZX09301305), the National High Technology Research and Development Program of China (863 Program, No. 2012AA020305), and the Program for Liaoning Innovative Research Team in University(LT2014023).

\section{REFERENCES}

1. Reya T, Morrison SJ, Clarke MF, Weissman IL. Stem cells, cancer, and cancer stem cells. Nature 2001; 414:105-11.

2. Clarke MF, Dick JE, Dirks PB, Eaves CJ, Jamieson CH, Jones DL, Visvader J, Weissman IL, Wahl GM. Cancer stem cells - perspectives on current status and future directions: AACR Workshop on cancer stem cells. Cancer Res 2006; 66:9339-44.

3. Al-Hajj M, Wicha MS, ito-Hernandez A, Morrison SJ, Clarke MF. Prospective identification of tumorigenic breast cancer cells. Proc Natl Acad Sci U S A 2003; 100:3983-8.

4. Singh SK, Clarke ID, Terasaki M, Bonn VE, Hawkins C, Squire J, Dirks PB. Identification of a cancer stem cell in human brain tumors. Cancer Res 2003; 63:5821-8.

5. Lee CJ, Dosch J, Simeone DM. Pancreatic cancer stem cells. J Clin Oncol 2008; 26:2806-12.

6. Ricci-Vitiani L, Lombardi DG, Pilozzi E, Biffoni M, Todaro M, Peschle C, De Maria R. Identification and expansion of human colon-cancer-initiating cells. Nature 2007; 445:111-5

7. Kelly K, Yin JJ. Prostate cancer and metastasis initiating stem cells. Cell Res 2008; 18:528-37

8. Sullivan JP, Minna JD, Shay JW. Evidence for selfrenewing lung cancer stem cells and their implications in tumor initiation, progression, and targeted therapy. Cancer Metastasis Rev 2010; 29:61-72.

9. Kim CF, Jackson EL, Woolfenden AE, Lawrence S, Babar I, Vogel S, Crowley D, Bronson RT, Jacks T. Identification of bronchioalveolar stem cells in normal lung and lung cancer. Cell 2005; 121:823-35.

10. Giangreco A, Groot KR, Janes SM. Lung cancer and lung stem cells-strange bedfellows? Am J Resp and Criti Care Med 2007; 175:547-53.
11. Yoshida A, Hs u LC, Dave' V. Retinal oxidation activity and biological role of human cytosolic aldehyde dehydrogenase. Enzyme 1992; 46:239-44.

12. Burger PE, Gupta R, Xiong X, Ontiveros CS, Salm SN, Moscatelli D, Wilson EL. High aldehyde dehydrogenase activity: a novel functional marker of murine prostate stem/ progenitor cells. Stem Cells 2009; 27:2220-8.

13. Ginestier C, Hur MH, Charafe-Jauffret E, Monville F, Dutcher J, Brown M, Jacquemier J, Viens P, Kleer CG, Liu S, Schott A, Hayes D, Birnbaum D, Wicha MS, Dontu G. ALDH1 is a marker of normal and malignant human mammary stem cells and a predictor of poor clinical outcome. Cell stem cell 2007; 1:555-67.

14. Huang EH, Hynes MJ, Zhang T, Ginestier C, Dontu G, Appelman H, Fields JZ, Wicha MS, Boman BM. Aldehyde dehydrogenase 1 is a marker for normal and malignant human colonic stem cells (SC) and tracks $\mathrm{SC}$ overpopulation during colon tumorigenesis. Cancer Research 2009; 69:3382-9.

15. Lugli A, Iezzi G, Hostettler I, Muraro MG, Mele V, Tornillo L, Carafa V, Spagnoli G, Terracciano L, Zlobec I. Prognostic impact of the expression of putative cancer stem cell markers CD133, CD166, CD44s, EpCAM, and ALDH1 in colorectal cancer. British journal of cancer 2010; 103:382-90.

16. Carpentino JE, Hynes MJ, Appelman HD, Zheng T, Steindler DA, Scott EW, Huang EH. Aldehyde dehydrogenase-expressing colon stem cells contribute to tumorigenesis in the transition from colitis to cancer. Cancer research 2009; 69:8208-15.

17. Prince ME, Sivanandan R, Kaczorowski A, Wolf GT, Kaplan MJ, Dalerba P, Weissman IL, Clarke MF, Ailles LE. Identification of a subpopulation of cells with cancer stem cell properties in head and neck squamous cell carcinoma. Proc Natl Acad Sci U S A 2007; 104:973-8.

18. Tanei T, Morimoto K, Shimazu K, Kim SJ, Tanji Y, Taguchi T, Tamaki Y, Noguchi S. Association of breast cancer stem cells identified by aldehyde dehydrogenase 1 expression with resistance to sequential Paclitaxel and epirubicin-based chemotherapy for breast cancers. Clinical Cancer Research 2009; 15:4234-41.

19. Van den Hoogen C, Van der Horst G, Cheung H, Buijs JT, Lippitt JM, Guzmán-Ramírez N, Hamdy FC, Eaton CL, Thalmann GN, Cecchini MG, Pelger RC, van der Pluijm G. High aldehyde dehydrogenase activity identifies tumorinitiating and metastasis-initiating cells in human prostate cancer. Cancer research 2010; 70:5163-73.

20. Visvader JE, Lindeman GJ. Cancer stem cells in solid tumours: accumulating evidence and unresolved questions. Nature Reviews Cancer 2008; 8:755-68.

21. Patel M, Lu L, Zander DS, Sreerama L, Coco D, Moreb JS. ALDH1A1 and ALDH3A1 expression in lung cancers: correlation with histologic type and potential precursors. Lung Cancer 2008; 59:340-9. 
22. Jiang F, Qiu Q, Khanna A, Todd NW, Deepak J, Xing L, Wang H, Liu Z, Su Y, Stass SA, Katz RL. Aldehyde dehydrogenase 1 is a tumor stem cell-associated marker in lung cancer. Mol Cancer Res 2009; 7:330-8.

23. Lin J, Haffner MC, Zhang Y, Lee BH, Brennen WN, Britton J, Kachhap SK, Shim JS, Liu JO, Nelson WG, Yegnasubramanian S, Carducci MA. Disulfiram is a DNA demethylating agent and inhibits prostate cancer cell growth. Prostate 2011; 71:333-43.

24. Zhang H, Chen D, Ringler J, Chen W, Cui QC, Ethier $\mathrm{SP}$, Dou QP, Wu G. Disulfiram treatment facilitates phosphoinositide 3-kinase inhibition in human breast cancer cells in vitro and in vivo. Cancer Res 2010; 70:3996-4004.

25. Morrison BW, Doudican NA, Patel KR, Orlow SJ. Disulfiram induces copperdependent stimulation of reactive oxygen species and activation of the extrinsic apoptotic pathway in melanoma. Melanoma Res 2010; 20:11-20.

26. Liu P, Brown S, Goktug T, Channathodiyil P, Kannappan V, Hugnot JP, Guichet PO, Bian X, Armesilla AL, Darling JL, Wang W. Cytotoxic effect of disulfiram/copper on human glioblastoma cell lines and ALDH-positive cancer-stem-like cells. Br. J. Cancer 2012; 107:1488-97.

27. Ma I, Allan AL. The role of human aldehyde dehydrogenase in normal and cancer stem cells. Stem Cell Reviews and Reports 2011; 7:292-306.

28. Xu B, Shi P, Fombon IS, Zhang Y, Huang F, Wang W, Zhou $\mathrm{S}$. Disulfiram/copper complex activated JNK/c-jun pathway and sensitized cytotoxicity of doxorubicin in doxorubicin resistant leukemia HL60 cells. Blood Cells Mol Dis 2011; 47:264-9.

29. Tardito S, Bassanetti I, Bignardi C, Elviri L, Tegoni M, Mucchino C, Bussolati O, Franchi-Gazzola R, Marchiò L. Copper binding agents acting as copper ionophores lead to caspase inhibition and paraptotic cell death in human cancer cells. J. Am. Chem. Soc 2011; 133:6235-42.

30. Li Y, Fu SY, Wang LH, Wang FY, Wang NN, Cao Q, Wang YT, Yang JY, Wu CF. Copper improves the anti-angiogenic activity of disulfiram through the EGFR/Src/VEGF pathway in gliomas. Cancer Letters 2015; 369:86-96.

31. Yip NC, Fombon IS, Liu P, Brown S, Kannappan V, Armesilla AL, Xu B, Cassidy J, Darling JL, Wang W.
Disulfiram modulated ROS-MAPK and NF- $\kappa$ B pathways and targeted breast cancer cells with cancer stem cell-like properties. Br. J. Cancer 2011; 104:1564-74.

32. Duan L, Shen H, Zhao G, Yang R, Cai X, Zhang L, Jin C, Huang Y. Inhibitory effect of Disulfiram/copper complex on non-small cell lung cancer cells. Biochem Biophys Res Commun 2014; 446:1010-6.

33. Monk M, Holding C. Human embryonic genes re-expressed in cancer cells. Oncogene 2001; 20:8085-91.

34. Rae C, Tesson M, Babich JW, Boyd M, Sorensen A, Mairs RJ. The role of copper in disulfiram-induced toxicity and radiosensitization of cancer cells. J. Nucl. Med 2013; 54:953-60.

35. Donita Brady, Matthew Crowe, Michelle Turski, G. Aaron Hobbs, Xiaojie Yao, Apirat Chaikuad. Copper is required for oncogenic BRAF signalling and tumorigenesis. Nature 2014; Volume:509:Pages:492-6.

36. Garber K. Cancer's copper connections. Science 2015; 349:129.

37. Johansson B. Stabilization and quantitative determination of disulfiram in human plasma samples. Clin Chim Acta 1988; 177:55-63.

38. Jeffrey Magee, Elena Piskounova, Sean Morrison. Cancer Stem Cells: Impact, Heterogeneity, and Uncertainty. Cancer Cell 2012; 21:283-96.

39. Antonija Kreso, John Dick. Evolution of the Cancer Stem Cell Model. Cell Stem Cell 2014; 14:275-91.

40. X Chen, L Zhang, X Hu, X Lin, Y Zhang, X Tang. Formulation and preparation of a stable intravenous disulfiram-loaded lipid emulsion. Eur. J. Lipid Sci. Technol 2015; 117:869-78.

41. Jiang F, Qiu Q, Khanna A, Todd NW, Deepak J, Xing L, Wang H, Liu Z, Su Y, Stass SA, Katz RL. Aldehyde dehydrogenase 1 is a tumor stem cell-associated marker in lung cancer. Mol Cancer Res 2009; 3:330-8.

42. Li Y, Zhang T, Korkaya H, Liu S, Lee HF, Newman B, Yu Y, Clouthier SG, Schwartz SJ, Wicha MS, Sun D. Sulforaphane, a Dietary Component of Broccoli/Broccoli Sprouts, Inhibits Breast Cancer Stem Cells. Clin Cancer Res. 2010; 16:2580-90. 